\title{
Air change rate in ventilated attics - reality and input for simulations
}

\author{
Eva B. Møller ${ }^{1,}$, Martin Morelli, ${ }^{1}$, and Thor Hansen ${ }^{1}$ \\ ${ }^{1}$ Danish Building Research Institute, Aalborg University, 2450 Copenhagen SV, Denmark
}

\begin{abstract}
To remove moisture by ventilating constructions is a wellknown strategy, used successfully in numerous facades and roofs. However, simulating ventilation is often difficult as convection in this case is in another dimension than what is usually in focus in 1D hygrothermal simulations. There are strategies for simulating ventilation in 1D programs assuming a fixed air change rate $(\mathrm{ACH})$. Unfortunately, $\mathrm{ACH}$ in roofs highly depend on wind direction and speed, hence a constant rate is a gross simplification. The article describes a comparative study between simulations with a 1D hygrothermal simulation program (WUFI) and simulations with BSim, a program in which the indoor climate can be simulated in different zones, in this case the ventilated attic. Focus is the effect of ACH in the attic on temperature and relative humidity. Finally, measurements of ACH in attics of ten single-family houses are presented. These measurements show that average $\mathrm{ACH}$ measured over more than two weeks differ very much from house to house although the ventilation openings in all houses seemed to be in accordance with current guidelines. Even measurements of the same attic differ considerably from time to time. The paper discusses what implications this should have on simulations.
\end{abstract}

\section{Introduction}

Natural ventilation of attics is a common used method to prevent moisture damage. The needed air change rate per hour $(\mathrm{ACH})$ in the attic depend on the outdoor air and the heat and moisture transport from below:

- If the roof is tight and build in moisture is dried out, the moisture content in the attic air is determined by the moisture content in outdoor air plus moisture that has entered the attic from below.

- The temperature in the attic is determined by the outdoor temperature, radiation, ventilation rate and heat flux from below.

Vapour barriers are often installed to reduce the moisture amount; it inhibits moisture transport by convection (airtightness), and by diffusion (vapour tightness). As warm air can contain more moisture than cold air, heating the attic would mean that more moisture could be removed with the same ACH. Unfortunately, heating the attic air would mean very little insulation material in the ceiling or alternatively installation of a small heating device like in some crawl spaces, however for energy reasons both methods should be avoided. It is important to find the needed ventilation openings to ensure sufficient ventilation of the attic to prevent moisture damage like mould growth. Guidelines describe the needed openings, e.g. in Denmark the rule of thumb has been a total opening area of at least $1 / 500$ of the floor

\footnotetext{
* Corresponding author: evm@sbi.aau.dk
} 
area, in pitched roofs that correspond to $1 / 2000$ at the eaves (each side) and 1/1000 near the ridge. Descriptions that are more specific are available for typical roofs [1].

Simulations can be used for predicting hygrothermal behaviour of ventilated attics, this is relevant if constructions deviate from well-known constructions or boundary conditions change e.g. if climate change is to be considered. Among practitioners, most simulations are performed in 1D because it is relatively easy and fast. However, ventilation is a transport mechanism in another direction than the 1D simulation, therefore, simulation programs have different ways to handle the $2 \mathrm{D}$ problem in $1 \mathrm{D}$, usually based on a constant $\mathrm{ACH}$. Unfortunately, the $\mathrm{ACH}$ in the attic depends on wind speed and direction. Most 1D simulations are therefore gross simplifications. Simulations in more than 1D, including modelling the whole building, are possible, and are typically used by researchers e.g. [2], in these cases, it is possible to simulate natural ventilation in attics i.e. $\mathrm{ACH}$ depending on wind speed and direction.

To determine the difference in outcome of the simplified 1D simulations and more sophisticated simulations with whole-building models, simulations with WUFI (1D) [3] and BSim (whole-building simulation) [4] have been made and compared to measurements. The aim is to clarify, if the gain in precision by whole-building simulation models is worth the effort compared to simpler 1D simulations. Finally, $\mathrm{ACH}$ has been measured in different houses to determine variations and to find a realistic level for $\mathrm{ACH}$.

\section{Methods}

\subsection{Description of cold ventilated attic}

\subsubsection{Model for simulations}

To compare different simulations with measured data a typical construction of a cold ventilated attic was chosen, the construction is shown in Fig. 1.

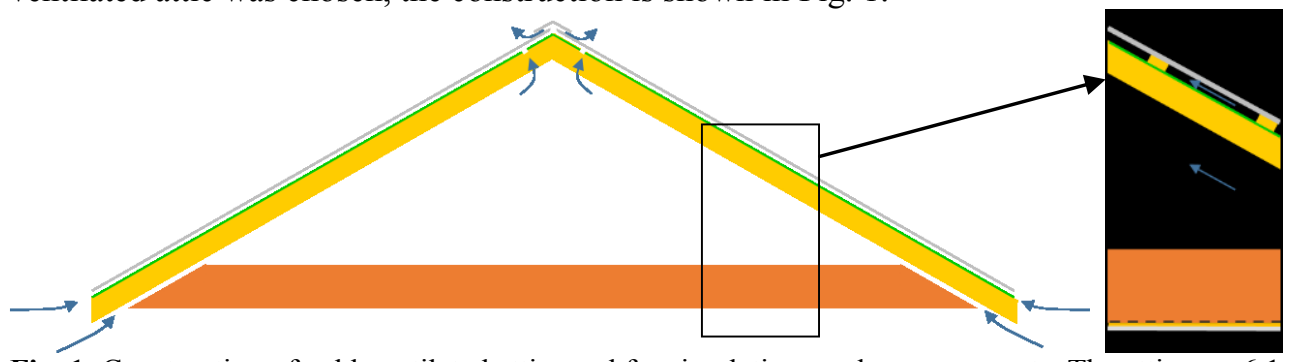

Fig. 1. Construction of cold ventilated attic used for simulations and measurements. The attic was 6.1 $\mathrm{m}$ wide and had an internal height of $1.8 \mathrm{~m}$. The roof was grey steel sheets with a diffusion tight roof underlay and ventilation between the two layers. The ceiling consisted of $400 \mathrm{~mm}$ insulation material (mineral wool with $\lambda$ - value of $0.039 \mathrm{~W} / \mathrm{m} \mathrm{K}$ ) with a vapour barrier (Z-value $=500 \mathrm{GPa} \cdot \mathrm{m}^{2} \cdot \mathrm{s} / \mathrm{kg}$ ), backing laths and $12 \mathrm{~mm}$ gypsum board. The attic was ventilated through openings in the eaves (260 $\mathrm{cm}^{2} / \mathrm{m}$ on each side) and through valves in the roof underlay near the ridge $\left(50 \mathrm{~cm}^{2} / \mathrm{m}\right.$ on each side). Furthermore, the ridge had openings, due to the shape of the steel sheets. The roof was north/south oriented.

A full scale test house had different $1 \mathrm{~m}$ attic sections, one of them was similar to this model, measurements from this section was used to compare with 1D simulations with WUFI. Furthermore, a comparison between the WUFI 1D and BSim was performed. Several BSim models were used; with three different constant $\mathrm{ACH}$ and one model with natural ventilation, i.e. where BSim calculated the air change rate in the attic.

\subsubsection{Climate}

Each simulation program require a set of input parameters; material parameters as well as indoor and outdoor climate. The needed inputs for the two chosen programs were different. 
E.g., the outdoor climate for BSim needed barometric pressure, which was not needed for WUFI simulations, and the weather files for BSim did not contain rain data. To compare the two programs with the same weather on both interior and exterior surface, the weather files for BSim were converted into files that could be used in WUFI. The weather files in BSim were based on Danish Design Reference Year [4], weather files for WUFI were obtained from Meteonorm [5]. Rain was left out, as the roofing was considered watertight.

In WUFI simulations, the indoor climate was simulated according to humidity class 2 , described in [6] for maritime climates. In the test house the indoor climate was changed twice a year; the relative humidity $(\mathrm{RH})$ was set to $50 \% \mathrm{RH}$ from November to May, and $60 \% \mathrm{RH}$ the rest of the year, see Fig. 2. In BSim, the indoor climate followed the climate in the test house, see Fig. 2, but as curves instead of steps.

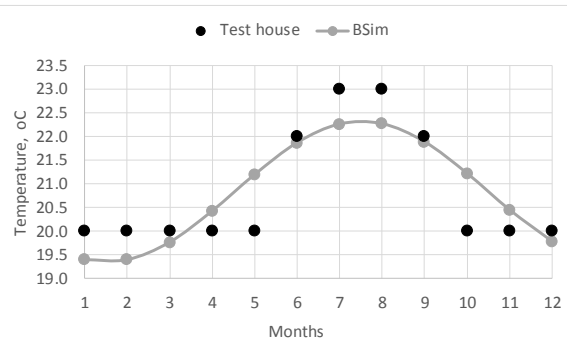

a)

Fig. 2. a) Temperature and b) moisture content in the simulated indoor climate (BSim) and the test house. The BSim indoor climate changed for each day, however temperature and RH were constant in each time step of a day. The test house indoor climate was the same in each day of the month.

\subsection{Simulations with WUFI}

WUFI calculates transient coupled heat and moisture transport [3] and is one of the most user-friendly simulation programs available [7]; in this case the 1D version WUFI pro 6.2 was used. The ventilated attic was modelled in WUFI as a 1D simulation with an air gap, consisting of three layers, where the middle part had no moisture capacity and the moisture supply from below was simulated by a moisture source in the bottom air layer. The method is described in [8] and [9]. After the model was built, an ACH and moisture supply from the room below the ceiling had to be estimated. For this calibration, measured data was used, resulting in two scenarios: $\mathrm{ACH}=6 \mathrm{~h}^{-1}$ combined with moisture supply of $2850 \mathrm{~g} / \mathrm{m}^{2}$ per year and $\mathrm{ACH}=9 \mathrm{~h}^{-1}$ combined with moisture supply of $4000 \mathrm{~g} / \mathrm{m}^{2}$ per year. The moisture supply was distributed over the month November until April (both included). WUFI is able to calculate how to distribute the monthly supply based on the climate file.

First, temperature and RH based on measured data and WUFI simulation with WUFI weather data file from [5] (close to the observed weather) were compared. The actual weather was not used, as not all required parameters were measured. Secondly, converted BSim weather files were used in WUFI simulations that was otherwise identical to the first simulations. These second WUFI simulations were used to compare with BSim simulations, also using BSim weather files.

\subsection{Simulations with BSim}

The Building Simulation programme BSim [4] was used to simulate the hygrothermal behaviour in the ventilated attic with two different ventilation strategies. First strategy was to permit ventilation by infiltration with a fixed ACH of $5 \mathrm{~h}^{-1}, 30 \mathrm{~h}^{-1}$ or $100 \mathrm{~h}^{-1}$. Second strategy was to employ the natural ventilation module, where ventilation is obtain through openings at top and bottom of the attic. BSim is a transient whole-building simulation tool to calculate among others: thermal indoor climate, energy consumption and synchronous simulation of moisture and energy transport in constructions and spaces. The geometry was 
modelled in 3D, where the attic was $1 \mathrm{~m}$ wide, with gables of $300 \mathrm{~mm}$ insulation, vapour barrier and $16 \mathrm{~mm}$ spruce to eliminate the impact from the outdoor climate. The geometry of the openings at the ridge were modelled as $0,1 \times 0,05 \mathrm{~m}$ and at the eaves as $0.035 \times 0,74$ $\mathrm{m}$. The model did not include moisture supply from below.

\subsection{Measurement of hygrothermal conditions in cold ventilated attics}

A full-scale test house with an attic section as shown in Fig. 1 was available. Indoor climate was controlled as shown in Fig. 2. Sensors of the type HTemp-1 wire from HWgroup were mounted in the attic. Temperature and $\mathrm{RH}$ was recorded hourly. According to the manufacturer [10] the temperature accuracy was $\pm 1.0{ }^{\circ} \mathrm{C}$ (between $-10^{\circ} \mathrm{C}$ and $+70{ }^{\circ} \mathrm{C}$ ) and $\pm 2.5 \%$ RH (between $20-80 \%$ ).

\subsection{Measurement of air change rate}

Measurements of $\mathrm{ACH}$ in the ceiling were performed in the test attic and in ten different single-family houses with passive tracer gas, PFT (Perfluorocarbon) over a period of 2-3 weeks. The method is described in [11]. Two different passive gasses were used, one in the ventilated attic and one in the room below the ceiling. The sources emitted constant amounts of gasses. Samplers, which also were placed in the two spaces, collected emissions. Based on the collected amount, ACH could be calculated. The ten houses all had attics like the test attic; ventilated from eaves to ridge with similar openings and the whole attic as one unused room. However, the geometry, orientation and location differed.

\section{Results}

\subsection{Simulations and measurements}

The results of measurements and simulations are shown in Fig. 3 and Fig. 4 as one-week running mean of the determined temperature and RH. Measured values are denoted "meas" while WUFI and BSim simulations are denoted "WU" and "BS" respectively. The number before h-1 is the constant $\mathrm{ACH}$ in simulations, while NV denotes natural ventilation, i.e. ventilation determined by BSim based on wind speed and direction.

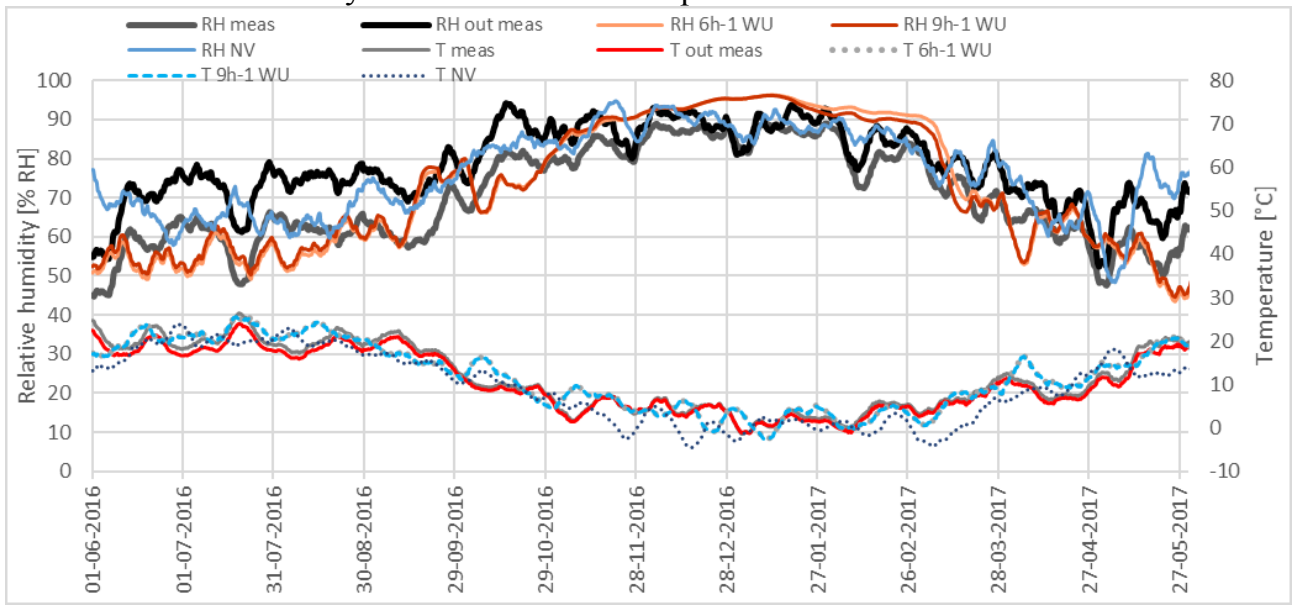

Fig. 3. Comparison of temperature and RH measured in the test house and outdoor, WUFI simulation with weather file from Meteonorm and BSim simulation with natural ventilation. Temperature from the two WUFI simulations (ACH $6 \mathrm{~h}^{-1}$ and $9 \mathrm{~h}^{-1}$ ) are almost overlapping and therefore difficult to distinguish. This is also the case for the temperature measured in the attic and outdoor.

\subsection{Air change rate}

$\mathrm{ACH}$ was measured three times in the test attic and once in the single-family houses. Table 1 shows the results of the measurements and the simulation with natural ventilation. 


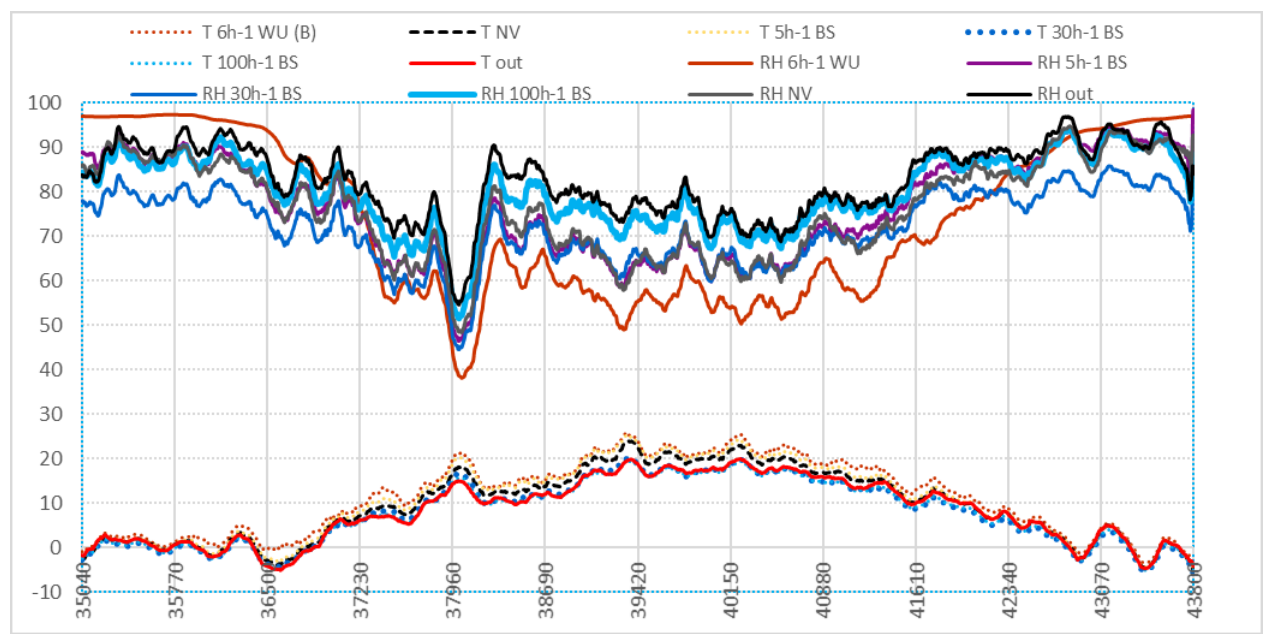

Fig. 4. Comparison of simulated temperature $\left({ }^{\circ} \mathrm{C}\right)$ and $\mathrm{RH}(\% \mathrm{RH})$ in the attic in the fifth year of simulation, starting Jan $1^{\text {st }}$. One simulation with WUFI (WU) and four with BSim (BS). The same weather files (from BSim) were used in all simulations. Simulation with WUFI with ACH of $9 \mathrm{~h}^{-1}$ almost overlapped the WUFI simulation with ACH of $6 \mathrm{~h}^{-1}$ and was omitted.

Table 1. ACH measured in single-family houses and test attic and calculated in a BSim simulation. 'max.' and 'min.' represents maximum and minimum two weeks running mean values.

\begin{tabular}{|c|c|c|c|c|c|c|c|c|c|c|c|c|c|c|}
\hline & \multicolumn{11}{|c|}{ Measurements } & \multicolumn{3}{|c|}{ Simulations } \\
\hline 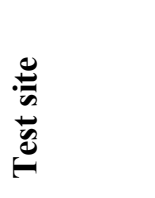 & $\begin{array}{l}\varangle \\
0 \\
0 \\
0 \\
0 \\
0 \\
\end{array}$ & $\begin{array}{l}n \\
0 \\
0 \\
0 \\
0 \\
1\end{array}$ & $\begin{array}{l}0 \\
0 \\
0 \\
0 \\
0 \\
0 \\
\end{array}$ & $\begin{array}{l}0 \\
0 \\
0 \\
0 \\
0 \\
\end{array}$ & $\begin{array}{l}1 \\
0 \\
0 \\
0 \\
0 \\
0 \\
\\
\end{array}$ & $\begin{array}{l}1 \\
0 \\
0 \\
0 \\
0 \\
0 \\
1\end{array}$ & $\begin{array}{l}0 \\
0 \\
0 \\
0 \\
0 \\
0\end{array}$ & 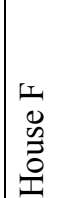 & $\begin{array}{l}\widetilde{1} \\
0 \\
0 \\
0 \\
0 \\
\end{array}$ & $\begin{array}{l}\stackrel{2}{0} \\
0 \\
\tilde{O} \\
0 \\
\end{array}$ & 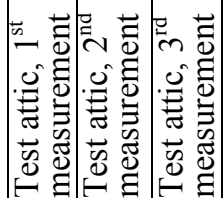 & 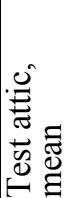 & 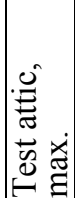 & 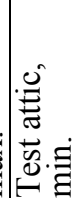 \\
\hline $\operatorname{ACH}\left(h^{-1}\right)$ & 16 & 6.1 & 8.2 & 22 & 24 & 21 & 2.7 & 6.5 & 3.8 & 1.9 & \begin{tabular}{|l|l|l|}
4.1 & 11.1 & 6.1 \\
\end{tabular} & 13.7 & 62 & 0.0 \\
\hline
\end{tabular}

\section{Discussion}

It was possible to make a $1 \mathrm{D}$ simulation with WUFI that fitted the measured values of temperature and $\mathrm{RH}$, although the simulation was made with a slightly different weather (reference year from [6]) instead of the actual weather. However, the simulation is not a blind simulation; the desired outcome was known and the simulation was calibrated to the measured values. The simulation overestimates the moisture in the winter slightly; maybe the moisture supply from below should be distributed with a little less in the midwinter, and more in spring and summer. The simulations with two different ACHs and moisture supply from below showed that if the moisture supply is increased, more ventilation could remove the extra moisture from below. This might only be true within a certain range of ventilation, as [12] showed that too much ventilation combined with undercooling causes high RH.

Simulations with BSim with fixed ACH confirmed this, as the BSim simulation with $\mathrm{ACH}$ of $100 \mathrm{~h}^{-1}$ showed higher RH than the one with ACH of $5 \mathrm{~h}^{-1}$. On the other hand, the simulation with $30 \mathrm{~h}^{-1}$ was in between the two others; similar to $100 \mathrm{~h}^{-1}$ in the winter and similar to $5 \mathrm{~h}^{-1}$ in the summer. The simulation with $30 \mathrm{~h}^{-1}$ was very similar to the simulation with natural ventilation, except in the winter where the RH was lower when simulated with constant $\mathrm{ACH}$. Although simulation with natural ventilation shows that the $\mathrm{ACH}$ is far from constant, simulation with constant $\mathrm{ACH}$, which is simpler, may give similar result. The difficult part for the practitioner is to choose the correct constant $\mathrm{ACH}$. There was no 
indication that $30 \mathrm{~h}^{-1}$ would be the best fit; it was just an educated guess. In other attics, another guess might be better.

That $\mathrm{ACH}$ varies even in the same attic is confirmed by the three measurements in the test attic made in three periods. The oldest and the newest measurements are alike, see Table 1, while the second measurement was more than twice as high. This corresponds to the simulation of $\mathrm{ACH}$ with natural ventilation, where the difference in maximum and minimum of mean values over two weeks were considerable. Consequently, simply to measure the ventilation rate may not give a reliable hint of a realistic mean $\mathrm{ACH}$. This could explain why the ACH in the attics of single-family houses differ by up to a factor 10 .

The calibrated 1D simulation with WUFI showed lower $\mathrm{RH}$ in the summer than simulations with BSim, while the RH in the winter was higher. This corresponds to the findings in Fig. 3, where the WUFI simulation overall fitted the measured values but with higher relative humidity in the winter and lower in the summer. In the winter BSim simulations with natural ventilation make the best fit, while BSim with constant ACH rate underestimated the relative humidity. Therefore, when using constant $\mathrm{ACH}$ the truth may between the BSim and the WUFI simulations. This is important to know when estimating the risk of mould growth.

\section{Conclusion}

This study showed by measurements and simulations that ACH in attics is far from constant even when considered over two weeks. Simulation with constant ACH may give similar results as simulations in the whole-building simulation program BSim with natural ventilation, however highly dependent on a correct estimate of the constant $\mathrm{ACH}$. Too high ventilation may give too high RH compared with measurements while too low ACH could result in to low RH in the winter. The practitioner must keep this in mind when making simplified simulations of ventilated attics, although the differences may be small.

\section{References}

1. E. Brandt, SBi guideline 224, (2013)

2. V.M. Nik, A.S. Kalagasidis, E. Kjellström. Build. and Environ. 55 (2012)

3. Fraunhofer. https://wufi.de/en/software/wufi-pro/WUFI

4. SBi: http://www.sbi.dk/indeklima/simulering/bsim-building-simulation/copy _of_artikler-og-papers/artikler-og-papers (2019)

5. Meteonorm : https://meteonorm.com/ (2019)

6. EN ISO 13788 (2012)

7. S. O. Mundt-Petersen, Report TVBH-1021 LTH (2015)

8. S. O. Mundt-Petersen, L-E Harderup. Build. and Environ. 90 (2015)

9. O. Eriksson, Examensarbejde TVBH-5097 LTH (2017)

10. HWgroup: https://www.hw-group.com/device/hwg-ste. (2019)

11. P. Heiselberg, N.C. Bergsøe, Int. Symp. on Room Air Convec. \& Vent. Effect. Tokyo, Japan. (1992)

12. A. K. Sasic. Thesis for deg. of doc. Chalmers Uni of Tech, Sweden, 2008 